\title{
A Comparative Study of Executive Guaranty of Arbitration at International Law (International Court of Arbitration and the New York Convention) and Iranian Law
}

\author{
Shila Taheri ${ }^{1} \&$ Hassan Soleimani ${ }^{1}$ \\ ${ }^{1}$ Department of Law, Law Faculty, Islamic Azad University,Damghan Branch, Damghan, Iran \\ Correspondence: Hassan Soleimani, Department of Law, Law Faculty, Islamic Azad University,Damghan \\ Branch, Damghan, Iran.
}

Received: April 28, 2016 Accepted: May 10, 2016 Online Published: June 29, 2016

doi:10.5539/jpl.v9n5p145 URL: http://dx.doi.org/10.5539/jpl.v9n5p145

\begin{abstract}
The present study is an attempt to analyze the executive guaranty of arbitration at international law within internal Iranian law and the international law. The present research findings show that within internal law in case the arbitration verdict is not carried out voluntarily then its obligatory administration is under the support of law and has legal executive guaranty. But arbitration privilege at administration stage is not limited to the fact that any arbitration verdict is to be performed without any questioning but a significant aspect of this privilege is to prevent the administration of a verdict which is altered or creased and openly against the facts or the law. In international law the international commerce chamber arbitration system is the most important international trade arbitration system in contemporary period and has always been the influential forerunner in international arbitration and has had a significant role in the development and expansion of arbitration method of settling international trade disputes. Both the chamber arbitration rules and arbitration verdicts which are issued under the chamber arbitration framework are among the most important legal resources in terms of international arbitration and are considered as the constructive and formative factors of international arbitration procedure. It should be mentioned that commerce chamber arbitration organization lacks the executive tools to execute the arbitration verdicts. But in spite of that on the basis of arbitration rules article 35 the arbitration authority and the chamber arbitration court makes attempts to execute the verdict and the purpose is mostly the official measures rather than judicial or administrative. Principally, the execution of arbitration verdicts depend on state rules and regulations where from the identification and administration of verdict is requested.
\end{abstract}

Keywords: arbitration, execution guaranty, international arbitration court, commerce chamber, execution of judgments

\section{Introduction}

Arbitration has a long history. The settlement of dispute by the agreement and following the decision made by the third party, who is trusted by the claim sides that is arbitration even before the codification of law in human communities or the establishment of any court or the arrangement and planning of legal principles existed in advance. However, from Second World War afterwards international trade arbitration has become a <justice technology> (methods of dispute resolution). Lack of execution guaranty in international law the same as what is in practice in international law system and in fact describing international legal rules to the execution guaranty in national lay systems has lead to suspicion about the status of international law system. While the solidarity and gradual evolution of national communities in terms of the legal rules along with execution guaranty has been the result of and evolutionary process of historical dynamics. International law because of novelty and the structural weakness and deficiency of rules and the diversity and variety of new subjects and the developments of international scenery beyond the traditional issues does not have sufficient administration guaranty and the confrontation with international parameters violations have not been dealt with adequately. Despite the lack of apposite executive guaranty the ruling regulations of the international society are required to be observed and their application affects the behavior of states and states follow the rules of international law in practice. Because, the requirement of an international society and the condition of its duration and stability is the vast observance of international law a procedure which is inevitable because of the variable identity of the international relations and the evolved structure of the international system. The present study is an attempt to analyze the arbitration 
execution guaranty in international law by the emphasis on international commerce arbitration chamber and New York convention of identification and execution of foreign arbitration rules (1958) and Iranian law.

\section{Arbitration}

Arbitration in terminology refers to judgment, sentence, adjudication, government and verdict. It is said that arbiter is originally justice-aid that is the owner of justice that over time and because of over use and ease of pronunciation the second $d$ is omitted and is used as the (davar) arbiter. Arbiter is the person who judges over the issue referred to him and decides who is right and who is wrong in a claim and gives his opinion (Note 1).

Arbitration refers to the resolution of disputes between litigants outside the court by legal or natural persons are either consensual or appointive (Note 2). The agreement between the sides on the basis of the fact that all or some of the differences that have happened between them or that it might happen refer them to the arbiters (WIPO arbitration rules) (Note 3). Arbitration agreement is sometimes in the form of an independent contract and sometimes in the form of arbitration condition. The second type of the arbitration is more common and therefore, we see that there is a talk of arbitration condition.

\subsection{Arbitration in Iranian Law}

In this part the arbitration in Iranian law is analyzed.

\subsubsection{Arbitration Agreement}

Arbitration agreement is an agreement between the sides based on which all or part of the disputes over one or some definite legal relation either contractual or non-contractual has happened or may happen, is referred to the arbitration (Note 4). Civil procedure between the arbitration and arbitration agreement or at least the approval of arbitration which happened in advance to the dispute and the agreements following the occurrence of dispute has differentiated (Note 5); but the f part of the article one has not accepted this differentiation.

On the basis of this article: "Arbitration agreement is an agreement between the sides based on which all or part of the disputes over one or some definite legal relation either contractual or non-contractual has happened or may happen, is referred to the arbitration" (Note 6).

Arbitration agreement has also been defined in part $\mathrm{g}$ of the Iran arbitration chamber service center in terms of the internal and external trade disputes settlements as: "arbitration agreement is an agreement between the sides on the basis of which the settlement of disputes over one or some issues of an agreement or non-agreement which has happened or might happen in future is referred to the arbitration of the arbitration center. The agreement might be in the form of arbitration condition along with the contract or in a separate contract".

\subsubsection{Types of Arbitration Agreement}

As it is expected from this part agreement to refer the issue for arbitration has different types. The sides can agree that that the future disputes about the agreement or the legal relation be settled via arbitration. This can be fulfilled by a condition within the contract or as an independent agreement. And also after the occurrence of a dispute whether referred to the court or not agree on the reference of the case to the court (Note 7).

Arbitration agreement is one of the arbitration agreements. The main base and infra structure of the arbitration is the agreement of the sides. This agreement in both types of the arbitration (1- arbitration condition along the main agreement and 2- independent arbitration agreement) but in one (agreement with condition) is limited and the other (independent arbitration agreement) is more expansive. Compromise to refer the dispute to the arbitration is called arbitration contract. The aforementioned contract exists in two types (Note 8).

\subsubsection{Submission Agreement}

This type of arbitration contracts has a separate physical existence from the main contract (Note 9). The sides of the case in this type of arbitration contract in an independent way intend to settle their disputes through this contract (Note 10). In case the sides had dispute over the original contract the arbiter would judge on the basis of that independent contract. And the second part of the article 455 of the civil law which states that "the dealers can be bound on the basis of the contract or on the basis of a separate contract make agreement that in case of the occurrence of any dispute they refer to the arbiter and determine" is a reference to this fact.

On the basis of the article 454 of the civil law all of the persons who have the eligibility of filing an action can by mutual agreement whether their case is referred to the court or not or whether it is in the process of verification or refer it to the arbitration of one or several people".

The aforementioned contract in this article would be concluded only when the dispute has happened and the disagreement has occurred and make s no difference whether it has been mentioned in states authorities or not 
and in case of reference it is at verification stage or revision stage and event the case has been verified at the supreme court there is a chance of agreement via arbitration and the article 494 of the civil law states that: "in case the case is at the stage of conclusion and the sides by mutual agreement request the reference of the case to the arbitration or that the case is identified as the case apposite for arbitration the supreme court would send the file for arbitration to the conclusive verdict issuing court that has requested".

On the other hand on the basis of articles 454 and 455 of the civil law the sides of the agreement can mutually decide on sending it to the arbitration of one or several people to resolve all their disagreements which have happened from a certain legal relation or it might happen, whether it has been contractual or not whether the subject of dispute has happened at the judiciary authority or not and in case of verification at any stage (the primary court or the revision court).

It is axiomatic that the arbitration agreement in proportion to the rights which are not dependent on the legal results that are not dependent on the will power of the sides but depends on the willpower of the third party such as the state etc. it would not be influential such as the case where the dispute case is against the public order such as the robbery and fraud any type of private agreement which cancels the public aspect of the crime would be invalid. The purpose of the arbitration agreement is any type of arbitration agreement on the basis of which the sides have become responsible to refer the dispute in between them to the arbitration and it is the condition of referring to the arbitration on the basis of which the sides have become responsible to refer their disputes in future to the arbitration. The starting date of the arbitration is when the disputed case is referred to the arbitration and the arbiter has announced the approval of arbitration. The sides of the case can also compromise in another way (Note 11).

\subsubsection{Arbitration Clause Next to the Main Agreement}

The other form of arbitration agreement is in a conditional way within the original structure of the agreement which is more in practice and it is called arbitration clause (Note 12). Apparently it has no separate existence from the main contract. This condition refers to the disputes which would happen because of the administration or the interpretation of the main contract in future (Note 13). Arbitration clause type of arbitration agreement happens when two or some people while doing a deal become responsible that in case of the occurrence of dispute refer to the arbitration (Note 14). Therefore, this type of arbitration is agreed only when there is no dispute or fight and may not happen at all such as a rent agreement which has been arranged and state that in case of the occurrence of any dispute it can be settled via arbitration (or by the arbitration of Mr. or Mrs.).

Although the arbitration agreement before the occurrence of the dispute and disagreement usually happens with arbitration clause but the dealers can "....on the basis of a separate agreement compromise that in case of the occurrence of dispute between them they refer to the arbitration..." (Note 15)

\subsubsection{Characteristics of Arbitration Agreement}

\subsubsection{Irrevocableness}

Arbitration agreement can not be countermanded by one side of the case. In fact, regardless of the verdict article 472 civil law considering the right of cancelation for the sides by the purpose of arbitration to resolve the dispute, is in contradiction and on the basis of the article "after the arbiter arbiters determination, the sides have no right to dismiss them except by the mutual compromise". On the other hand the arbitration agreement can not be considered as essential because by the departure or the death of one side it is annulled (Note 16) while the article 954 civil law considers the cancelation of the agreement as a result of the departure or death.

The other possibility is to consider the necessity of the arbitration. So that considers the arbitration agreement as the indefinite agreement and then refers to the article 10 of the civil law and also the necessity principle.

The justification of article 481 of the civil law would also be the same because the arbiter in contrast to the judge gets his authority from the will of the sides whenever this will is removed the authority would also be removed and consequently the authority is eliminated. It seems that this possibility is also very weak because even in verification through the court the authority of the judge is from the will of the aides or at least from the will of the demanding party and even the death of one of the sides does not lead to the cancelation of the verification (Note 17). It might be stated that arbitration is a special agreement with special rules which might not be interpreted and analyzed through the licensing rules and the civil law necessity (Note 18). Arbitration agreement is a necessary agreement therefore, it is in congruence with the first part of the article 481 of the civil law but the second part of it that is the cancellation of the contract with the death of one of the sides is not in proportion because the death of the sides does not have any influence in irrevocable agreement and the successor of the deceased should fulfill the commitments of the testator (Note 19). 
Although some believe in the necessity of the arbitration agreement but in contrast to the aforementioned agreements the voidable contract by the departure or the death of the one of the sides is removed (Note 20). Arbitration agreement is about the sides of the dealing and does not include the others beyond that although the non-heirs and the successor are responsible for the contract. It seems that the arbitration agreement is a necessary contract but since it depends on the person after the death of the person it is countermanded and if there is an exception it is removed by the death or departure of the person then article 481 of civil law has no conflict with being necessary and article 954 is special for permission contracts.

\subsubsection{Ceremonial}

Arbitration agreement needs to be written. In other case (oral) contract would only have the legal administrative guaranty that the opposite side of the arbitration agreement has approved and certified its existence by officially eligible authorities. It can be interpreted from the first part of the article 481 of the civil law which states that in the following cases the arbitration is countermanded in the following cases: 1- by the written compromise of the sides..." and since the arbitration cancelation needs to be written then its existence should also be written. The existence of the written document needs to be explicit from the other sides or the legal agent or the contract agreed by

In case the sides refer to the cancelation of arbitration agreement in the court or the arbiter it should be accepted that the arbitration agreement is considered as concluded. The writing condition of the arbitration agreement is only when necessary to be practiced that the existence of the arbitration agreement is suspected by the sides that in this case the arbitration agreement should be announced as countermanded. Lawyers and judicial agents and the company managers etc. merely on the basis of having agency from their clients can not and do not have the eligibility to conclude arbitration agreement and they need to present a special license from their clients or the respective foundation (Note 21).

It seems that the arbitration agreement is a ceremonial contract which needs to be written. Despite the civil law procedure silence the international trade arbitration law in its $7^{\text {th }}$ article refers to the necessity of written arbitration agreement on the basis of this article: "the arbitration agreement needs to be signed through a contract in between the sides or the exchange of letter, telex, telegram, or similar mechanisms referring to the aforementioned agreements. Or one of the sides via a request or defense claims its existence and the other side accept it in practice. The reference to a document within the agreement which demands the arbitration condition would also be considered as the audition agreement". In the article 5 of the arbitration law of England and also the article 1443 of the France civil law the necessity of the written arbitration agreement has been emphasized.

\subsubsection{The Relativity of the Impact of Arbitration Agreement}

The impacts of the arbitration agreement are limited to the beneficiary sides. On the basis of the article 495 of the civil law procedure "the verdict of the arbiter is become cancelled" eligible only for the sides of the contract and those engaged in the determination of arbiter and their successors and does not have any influence on other people". Similarly on the basis of article 219 of the civil law procedure "agreements which are arranged on the basis of the law between the dealers and their successors are necessarily to be followed or that on the basis of the compromise by the sides of the case become countermanded". The judgment of the arbiter in terms of the persons not related to the arbitration agreement has no effect. And for the same reason the verdict of the arbiter in terms of the third party is ineffective and in case the third party has no relation with the case under the verification the court should verify the case separately (Note 22).

There are also some instances within the judicial procedure confirming this fact. In the verdict number 965 of the 2003/6/16 of the revision court of Tehran province this fact has been explicitly referred to in a case where between those requesting adaptive revising to refer the arbitration for the revision court. After the conclusion of the verdict the party demanding revising the judgment on the basis of the fact that the arbitration agreement was not intended demanded the revision of the verdict by the court and the revision had concluded as: "given the all available documents of the file and considering the fact that in the contract of date... between revising side of the case and the other side the second column arranged for the agreement and the compromise to refer the dispute to the arbitration had not been done and in contract dating....which was between ....and... the revising court had no role in the case and the reference of the case to the arbitration which has been explicitly mentioned had no influence to the person and for this issue no complaint is acceptable...".

Article 72 of the arbitration law of England also has a similar verdict. On the basis of this article in case the verdict issued by the arbiter is effective for the third party and the aforesaid claimant is the lack of agreement in the determination of the arbiter it can be referred to the court. And also this person would have the same rights as the sides of the arbitration in complaining about the court decision and can announce the arbiter verdict as 
ineffective. Article 481 of the civil law procedure of France has also dealt with this issue to demand the invalidity of the arbiter's verdict from the competent court (Note 23).

\subsection{International Arbitration (New York Convention and International Arbitration Chamber)}

\subsubsection{International Arbitration Chamber}

The arbitration system of the International arbitration chamber was established four years after the foundation of the chamber in 1923. Preparation of arbitration rules and the establishment of arbitration tribunal chamber in such a short time show the fact that the policy makers and decision makers of the chamber from the day one were well aware of the fact that although the occurrence of differences between the traders and the merchants is a natural issue but if not resolved and handled in an apposite way it would be one of the obstacles of commercial exchanges and causes waste of time and expenses. On the other hand in search of the apposite methods and approaches of settling claims they found out that the commercial cases and claims at international level have special features and characteristics that they can not be handled in traditional ways by referring to the courts or the scattered arbitrations.

In fact the complex nature of these cases and the multi-layer nature of international claims caused by investment contracts require the resolution of the disputes by entrusted persons with required expertise and competence of the filed under the dispute (Note 24). Arbitration rules of the chamber are set of rules which are in fact the procedures of arbitration and determine the way to verify the claims. Arbitration rules were first arranged in 1923 at the same time with the establishment of the arbitration court and were passed by the global counsel. And later under the influence of the obtained experiences which were acquired practically were several times revised and corrected and after some corrections which happened in 1998 now they have almost comprehensive and complete rules. New chamber arbitration rules are first passed in the chamber management committee and later in the global chamber counsel (Shanghai congress April 1997) and finally became compulsory from 1998. Chamber arbitration rules covers the arbitration process from the beginning to the end of the verification and the announcement of the verdict. The most important feature of the chamber arbitration rules is the highest freedom of action and considers the freedom of action and selection for the sides and the referees over the arbitration process and has too much flexibility. These rules have determined special responsibilities and authorities for the organization chamber arbitration and particularly chamber arbitration court by this purpose to employ continual and efficient supervision on the arbitration process and prevent the occurrence of delays in verification of the cases and resolve the possible obstacles and dead ends in the process of arbitration. The main purpose of the recent changes in chamber arbitration rules one is to provide the speed of arbitration process and the omission of chamber arbitration rules and clarifying the chamber arbitration system and eliminating the previous ambiguities of the earlier rules and facilitating the arbitration process and third removing the shortages of the earlier rules such as the explicating the multiple sides arbitrations which are possible under the present rules.

\subsubsection{New York Identification and Administration Convention of Foreign Arbitration Rules (1958)}

This convention deals with the identification and administration of those arbitration rules that in the disputes between persons whether legal or natural persons within the territory of a state beyond where it has been demanded is issued and similarly is about the arbitration rules that are not considered as local rules within the state demanding the arbitration and the purpose of the arbitration rules is not only limited to the verdicts issued by the selected arbiters for every case but includes cases where the verdicts are issued by the permanent arbiters that the sides of the cases have referred to them for arbitration (Note 25). At the time of signing, or passing or appending to the present convention pr at the time of determining the territory of the influence of the judgment on the basis of the $10^{\text {th }}$ article of it every state can announce on the basis of the mutual dealing that exclusively would identify and administer them that are issued within the territory of the committed state. And can also announce that the convention would only be implemented in the cases where the disputes caused by legal relations of internal rules which are considered as commercial.

On the basis of the second article of the aforementioned convention the committed states will consider as official any written agreement that the sides on the basis of that have become committed to refer all or part of their claims or future cases to the arbitration and these claims caused by certain legal relations either contractual or else that the subject can be settled and resolved through arbitration. Written agreement is more general than arbitration condition which is recorded next to the contract or that a separate agreement has been signed by the sides or established via exchange or telegram.

Whenever a claim is verified in one corresponding country of the sides of the agreement where the sides concerning the main subject of the arbitration agreement of this article the court on the basis of the one of the sides assign an arbiter unless in cases where on the basis of the court decision the arbitration agreement is 
countermanded or devoid of effect or bereft of essential requirements for the administration (Note 26).

\section{Guaranty of the Execution of Arbitration According to the Internal Law}

Arbitration is among the cases that leads to the reduction of the size and time of the verification of the disputes and the arbiters are not limited by the civil rules and regulations of the civil law but needs to observe the rules related to the arbitration rules. Since the legislator has considered the guaranty of execution for the arbiter's verdict and the agreement of the sides tries to support the verdict of the arbitration therefore, the arbitration verdict needs to be in congruence with the legal principles and regulations especially the sections of article 482 of the civil law procedure of the 2000 which states that: The arbiter's verdict needs to be eligible and documentary and not to be against the right backing rules $>$ therefore the arbiter's verdict in addition to being apposite and rational should not be against the right baking rules so that possess the legal support of the execution and in case of the lack of two important elements, the arbiter's verdict lacks the execution function and can be countermanded in the judicial tribunals.

Execution guaranty of the arbitration verdict of the judicial authorities and via this way can be executed. Arbitration is a private foundation and the verdict of the arbiter to have execution guaranty have the explicit reference of it in the law and the chance of employing the law force for its implementation so that the government in line with securing the public order and no harm rule and the believer dignity can govern and administer the arbiter's verdict on the basis of the current rules and regulations. The differentiation between internal and foreign arbitration rules are important since the type of identification and execution of them for the local administration need to be in congruence with the article 662 of the civil law procedure and demand the execution from the court.

Internal arbitration refers to the arbitration that all of its constituting elements such as the arbitration identity, up to the nationality of the case sides and the arbiters, the place of the arbitration, the executable law and the place of execution of the verdict is related to a particular political and governmental territory for example when the arbitration issue is the settlement of dispute between two Iranian nationalities about a case which was in Iran and by the Iranian arbiters by observing Iranian law has been verified and the verdict is issued it is called the particular definition of arbitration. But it seems that this definition is no sufficient whether merely the lack of one of the aforementioned items to the aforesaid arbitration does not assign foreign quality. Unfortunately in Iranian law there is no norm to determine the arbitration verdict nationality and the purpose of the arbitration verdict nationality is to determine arbitration verdict by tolerance the country where the verdict belongs to (Note 27). The first guaranty of the arbitration verdict in the execution of all of the available and legal verdicts such as the internal arbitration law is justice and fairness. In Iranian law the justice and fairness is the definition originating from the conscience and instinct. The place of justice and fairness are cases where a sense of the balance of rights in human is stimulated and the wisdom and conscience verdict established the justice and fairness in this case. It seems that the first factor and guaranty of any verdict is the conscience, justice and fairness and the famous statements that conscience is the only court which requires no judge. The first internal guaranty of verdict execution is originated from the justice and fairness.

The most important guaranty of the arbitration verdicts is the voluntary execution of the verdicts which is one of the advantages of arbitration. From legal perspective the compromise and agreement on arbitration requires the subsidiary commitment of the sides that the sides are committed to observe the verdicts. In practice since the sides have voluntarily referred to the arbitration the losing party usually observes the verdict and rarely happens that the winning party has to refer to the judicial courts to resolve the case. Because both sides believe that the decision or verdict issued by the arbiter selected by them is the apposite and optimal decision to follow and there is no reason to refuse it. The voluntary execution of the verdict by the sides is both the cause of the compromise of the sides in referring to the arbitration and the necessary result. The sides of the agreement in advance agree that they accept the arbitration verdict whatever it is and respect it and administer it. If after the arbitration and the issuing the verdict for the execution of it that refers to the judicial tribunals and continue the verification process that would question the rational and philosophy behind the existence of it. To execute the authority of arbitration verdicts particularly in trade arbitrations there are some other causes and reasons. The first guaranty of the execution of the arbitration verdict in a voluntary way is the quality of arbitration execution. The arbitration method and the arbitration verdict is as efficient and optimal as the arbiters are selected and act properly in commercial field to preserve the dignity and honor of the merchants and traders. The voluntary execution of the arbitration verdict is the best evidence of the good will of the traders and their commitments and promises that they make (Noet 28).

In some of the professional associations, trade unions or trade chambers, there are some punishments for those 
refusing to follow the verdicts of the arbitration if a trader or a company because of disregarding the verdict of arbitration get union penalty and punishment the commercial credit and prestige of the company would be threatened.

In organizational arbitrations the arbitration verdict enjoys the support of the organization which assists the execution of the arbitration verdict. The trader or the organization that has become the losing party the next time the same organization be the arbitration ruler and therefore tries to execute the issued verdict.

The existence of internal rules and regulations or mutual and multiple treaties the significant incentive for the losing party to execute the arbitration verdict is the voluntary nature of the arbitration verdict as the guaranty of the execution arbitration. Sometimes it is stated that since the judgment is beyond the judicial system the decisions and verdicts do not have the stability of the court decisions and sometimes judges look at the verdicts with suspicion and for the same reason its administration is faced with difficulties and its execution is not as easy as the judicial judgments. The comprehensive answer to this question requires a comparison of the method of arbitration and judicial verification which should be done in due place.

Justice requires reference to the fact that part of the difficulties of the execution of the arbitration verdict is the inapposite performance of some of the arbiters and their unfamiliarity with the arbitration rules. It is true that arbitration is good as far as the arbiters are good. Because a large part of the arbitration privileges and advantages for the resolution and settlement of the problems of commercial disputes depend on knowledge, specialization, expertise and competence and apposite action of those assigned as the arbiter (Note 29).

\section{Guaranty of Execution in International Law}

\subsection{Guaranty of Execution in International Arbitration Chamber}

The primary agreement to refer the differences to arbitration refers to this fact that the issued verdict needs to be executed at the end. In case the arbitration verdicts do not get executed significantly or problems or difficulties happen in the process of execution the arbitration would be bereft of value and credit. Increasing development and expansion of international trade relationships in the world has considerably developed and increased the international trade arbitration and this calls for the execution guaranty of the arbitration verdict. The arbitration verdicts may be voluntary or obligatory.

Voluntary execution of the rules given the credit and respect allotted to the verified judgments are emphasized in all cases and this fact is emphasized in all international rules and regulations and texts of conventions and the sides and the states are required to respect the arbitration verdicts and eliminate the obstacles in the path of the administration of the rules.

As mentioned before the verdicts of international trade chamber is definite and compulsory (article 28 (6) rules). But the compulsory state of the verdict is different from its execution and in case the losing party does not observe the verdicts of the arbitration there is no choice but referring to the internal tribunals of the person's country or the place of the occurrence of the property and request the identification and the execution of the verdict. The execution of the verdict at this stage is on the basis of the internal rules and regulations of the country of the execution that to what extend consider it credible and then issue the execution verdict.

International commerce chamber arbitration does not have administrative tool to execute the verdicts of the arbitration. But according to the article 35 of the arbitration rules but on the basis of article 35 of the arbitration rules chamber arbitration tribunal and arbitration authority (ICC) does the required cooperation in terms of official measures rather than judicial and executive ones. Principally the arbitration execution issue is dependent on the state rules and regulations of the state from whose courts the identification and execution is demanded. At the present time international arbitration chamber is one of the largest and most significant international arbitration organizations whose purpose is to assist the economic development across the world and has a significant role in spreading arbitration in terms of resolution of international trade disputes. This chamber is a private and non-state organization which was established in 1919 in Paris. Hundreds of private companies in around 130 countries across the world are members of this foundation and the national committees of this chamber have been established in 86 countries of the world.

International arbitration court (ICC) is a foundation related to this organization which has been established to settle the international trade disputes through arbitration. International trade chamber has a unique role in terms of the expansion and development of the trade exchanges at international level by standardizing the policies and regulations such as incoterms and the international regulations such as the documentary credits, guarantees etc. and also the management of the largest organization that provides the foreign arbitration and the management of the largest international arbitration center. In this organization the type of the foreign arbitration its conditions 
and also the cases of lack of identification and lack of execution have been determined. In case the verdict has significant problems (such as the trespassing of the arbiter from the authorities or the public order etc.) can not be identified or executed. This organization all in all has considered a lot of facilities and requirements for the execution of the verdicts of the arbitration. Iranian international trade chamber was established in 1959 and after the revolution faced with a couple of years of interval in 1985 by the suggestion of the government and the attempts of the industries and mines ministry of Iran the new round of its activities started. At the present time in case a verdict by the international trade chamber arbitration is referred to the Iranian courts would be dealt with on the basis of the foreign rules execution of the general rules and regulations (such as the article 169 of the civil law procedure passed in 1977 and also the articles 972 afterwards of the civil law procedure). But the article 33 and 34 of the arbitration law has predicted that is special to international laws that are executed in Iran. But it can be practiced as the Iranian rules and regulation in terms of the international arbitration rules and it is in line with the judicial procedure to eliminate the ambiguities of this field.

Within the legal systems of the states all of the legal rules are respected and they are automatically followed without any need for the pressure from the government and this observance has different reasons and the most evident one is the close and strong possibility of the disastrous outcomes of avoiding the observance of the rules and within the international system also these are followed by the voluntary execution of the arbitration verdict might have various reasons and it is not always done by the serenity of mind.

For example, the existence of a national law or international convention in favor of the arbitration with preventive role of judicial procedure in terms of being appealable or the complaint to the execution of rules can be considered among these factors. Apart from the reasons which directly cause the execution of the arbitration rules authority here it is necessary to refer to the arbitration verdicts voluntary execution as $\mathrm{n}$ absolute meaning. The important issue in this respect is that the best guaranty of the execution of the verdict is the <quality of the arbiter's verdict $>$. In compulsory execution of the arbitration verdicts countries usually select one of the two methods.

First- a method similar to a foreign judicial verdict that through following a procedure such as obtaining the execution order

Second- a method which is more or less the same as a national arbitration verdict and through it the normal legal petition for obtaining approval of arbitration verdict and converting it into a court verdict is presented.

Some of the presented procedures in the rules have welcomed the identification and foreign rules execution and have been for the benefit of the arbitration, but generally the complexity of the suggested procedures and the presence of differences in terms of the legal systems leads to the complication and insecurity of the suggested solutions by the national rules and they are not for the benefit of the arbitration and the main reason and successful and specialized arrangement of international conventions are at this issue. Such as the articles 53-55 of the Washington convention 1965 have focused in terms of the compulsory nature of the verdicts for the sides of the case.

Article 53 states that: $<$ the verdict is compulsory for the sides... $><$ and any of the sides needs to observe the verdict contents and execute the verifications. Article 54 of the aforesaid convention has also emphasized the conclusiveness of the verdict in the territory beyond the border that is in front of the committed countries' internal courts have been confirmed.

The issued arbitration verdict under the convention has the value of the conclusive case in any of the contracting countries.

Article 55- Non of the aforementioned items in the article 54 should be considered as the derogation of the appealable rules of the contracting countries in terms of the executive responsibility of that country or any other foreign country. In the third article of the New York convention identification and execution 1958 has been asserted that:

The contracting countries would consider the arbitration rules as binding and would execute them on the basis of the local rules procedures where the arbitration verdict within the territory has been considered as exception by observing the mentioned conditions of the future articles of the convention..

In terms of the execution of the Iranian international trade arbitration law in article 35 states that:

With the exception of the articles 33 and 34 mentioned at the arbitration verdicts which are issued on the basis of the rules of this law are absolute and conclusive and after the announcement they need to be executed and in case of the written demand of the court the subject of the article (6) the requirements of the execution of the court rules are administered... 
Finally to recap the issues concerning the trade arbitration verdicts execution it can be stated that the surrounding problems of the execution of the verdicts particularly the execution of the rules through the pressure by the states not only consist the exceptional cases and the significance of these issues should not be considered more than the reality but they are not popular issues in terms of the arbitration that shows some of the rare violations in this issue and the execution of the verdicts either compulsory or voluntarily are two related issues and even complementing factors.

\subsection{Execution Guaranty of New York Convention}

Neither the nationality of the sides of the arbitration agreement nor the accommodation place has an effect on the execution of the New York Convention. In addition the convention in terms of the subject of the arbitration is not limited to the trade international relations but the member countries can make use of the condition and limit the coverage of the convention to trade relations. Part 1of the article 1 of the execution limits of the convention divides it into two groups of verdicts as follows:

Verdicts issued within the territory of a foreign country

Verdicts that are not considered as internal verdict within the arbitrating state territory

\subsubsection{Verdicts Issued within the Territory of a Foreign Country}

The regulations of New York convention can be applied for those arbitration verdicts that have been issued within the territory of a foreign country. This is the first criterion of the New York convention. It makes no difference whether the sides of the case are from the arbiter's country or not or both of them are foreign or one of them is foreign (Note 30). Also it makes no difference that the accommodation of the sides is located in which country and principally it makes no difference whether the country where the judgment is issued is a member of the convention or not. Therefore, whenever the arbiter of one of the member countries is demanded to issue the order of the execution of the arbitration verdict outside the territory of the arbiter the order is issued by considering the convention regulations.

It needs to be mentioned that articles 1-3 of the convention allows the member countries that anytime they wish make use of one of the two rights as follows: at the time of signing the passing or enjoinment to this convention or at the time of delivering the declaration which is mentioned in article 10 and make a condition that the rules of this convention as mutual dealing in terms of the execution of those arbitration verdicts will be observed that have been issued within the territory of one of the member countries.

They can also make a condition that they would observe the convention only in differences related to the legal relations, contractual and non-contractual that on the basis of their national law is considered as commercial.

Therefore, when a country at the time of signing an approval, enjoinment, or the later declaration does not make use of the first right then the conventional rules within the member country territory where the verdict has been issued but also in cases where the verdicts are issued within the territory of non-member states.

In the single article passed in 2001/1/21 by the Islamic council in terms of the incorporation of the Islamic Republic of Iran to New York convention both rights have been used. Although it seems that the use of the condition right $<$ mutual trade $>$ is not that reasonable. Because in a condition where 125 countries of the world have incorporated the New York convention and the countries that Iran has expansive trade with are members of the convention do not benefit from the condition right in practice.

New York convention can be implemented for those arbitration verdicts that have been issued outside. Therefore, when the sides of a contract where all of its elements are internal consider the arbitration outside the judge territory home country the issued verdict would be included in convention regulations. This issue provides a chance to cheat the law. Whether the sides of a contact willing to remove themselves from the internal rules of a state they can determine the arbitration place in another country but as stated by some scholars in case of the existence of fraud intentions the judge can under the coverage of the law remove the case from the coverage of the New York convention.

It should be attended that in some countries such as the United States of America on the basis of the New York convention the convention regulations in proportion to the concluded agreements between American citizens can not be practiced. Therefore two Americans can not by fraud to the law place their agreement under the New York convention coverage.

On the basis of the third part of the article 1 of the New York convention any of the member countries can set a condition that they would execute the convention only for those arbitration verdicts that have been issued within the territory <one of the member countries $>$. Therefore, those arbitration verdicts that have been issued in the 
territory of a country which is not a member of the New York convention would not be included in the convention rules. (Note 31 )

Iranian Oil Company and an American company in a contract that had signed before the Islamic Republic of Iran had agreed that in case of the difference the case should be referred to the arbitration and the place of the arbitration should be in Tehran and after the occurrence of the dispute after that the American company refused to have the arbitration place in Tehran.

Iran Oil Company asked American courts to force the opposite side to attend the compulsory court. The revision court of America in 1987 by this rationale that the American government at the time of incorporation to the convention has conditioned that it would execute those arbitration verdicts that have been issued in the territory of one of the member countries of the convention and given the fact that Iran is not a member of the New York convention the New York convention was announced as inapplicable.

The rational of the American court is on the basis of this view that whenever the arbitration process is done in Iran the arbitration verdict would also be issued in Iran. This rational is almost in line with the reality but by considering the fact that in the aforementioned file no verdict had been issued it can be argued. On the other hand it is possible that the arbiter make judgment in another country and the coutry of issuing is different from Iran.

\subsubsection{Arbitration Verdicts Bereft of the Quality of Internal Verdict of the Arbiter's State Territory}

According to the recent part 1 of the article 1 of the New York convention in addition to the arbitration verdicts which have been issued outside the arbitration verdicts that are not in congruence with the judge law as the internal verdict will be included in the New York convention. Such verdicts are called $<$ non-national $>$. But what is the non-national verdict? Non-national verdict is the one that is not considered as the internal judge law. But which verdict is not internal? It is clear that the answer to this question should be searched in the internal law. It can be assumed that the arbitration verdicts issued from international arbitration authorities such as Iran and America arbitration tribunal are not considered as internal in any other countries but to find out what verdict is considered as internal in any country we need to refer to the rules of that country.

In some of the rules basically there is no reference of internal and non-internal rules. Iran's international trade arbitration law is one of them. What has been defined within the law of Iran is the <international arbitration $>$. To make an inference from the law of Iran that which law is internal and non-internal it can be inferred that the arbitration verdict obtained from the <international arbitration $>$ is not an internal verdict and eventually the internal verdict is one that is not created by<international arbitration $>$. Therefore, those verdicts issued in Iran and that one of the sides of the agreement at the time of the contract conclusion is not a citizen of Iran the verdict is considered as non-internal and becomes part of the New York convention (Note 32).

\subsection{The Obstacles of Execution Guaranty of International Trade Arbitration Verdicts}

In this part the obstacles ahead of the execution of verdicts would be discussed

\subsubsection{Lack of Observing Trial Procedures}

In every trial the corresponding trial rules and procedures need to be observed such as the delivering the petition either in an actual way or legal, unbiased trail, exchange of bills, regular trial sessions administration, precise defense analysis and the documents of the sides, that lack of following these regulations is considered as the verdict of foreclosure defense of the losing party and the issued verdict even eligible in other aspects and can be executed in the issuing country it would not have the beyond the border effect.

For example, part 1 of the article 52 of the Washington convention 1965 is in line with this issue.

d- In case the trial procedures have been abandoned (violated)

h- In case the reasons for issuing the verdict have not been mentioned

\subsubsection{The Contradiction of Verdict with Public Order}

The definition of public order is different from time, place and person in a country different establishments and organizations are usually arranged with tune and the legislator normally consider all and every aspect of the issue and legislates a law which is congruent with the society and that the environment is apposite for the execution the power of legislation is from the same society and has the complete familiarity with the religious rules and historic and ethical background of the legislation over the processes in the society. Therefore, when the execution of the verdicts from foreign courts causes damage to the public order of the execution place as an absolute legal rule such a verdict can not be identified and administered. 
Part 2 of the section $b$ of the article 34 of the law can be referred as an instance of the international trade arbitration law incongruent with the public order as one of the reasons of countermanding which is considered as the only way of complaining to the issued verdict and the execution of the verdict.

Part b of the section 2 of the article 5 of the New York convention 1958 has stated to the incongruence of verdict and the public order as one of the reasons of rejecting the identification and execution request (Note 33).

\subsubsection{The Conflict of the Issued Verdicts}

Lack of single rules and regulations in terms of the eligibility among various countries there is a possibility of eligibility of two countries' courts about a single issue and as a result it is possible that a single case is verified in both countries and end up in issuing contradictory verdicts. Some of the lawyers believe that the courts in the face of such verdicts should act the same as passed laws on single issues.

That is by the verdict of no right the previous law gets annulled but this view is not legally justified.

Article 376 of the new civil law procedure in terms of the various verdicts on a single issue states that $<$ in case in a subject various verdicts are issued without the sides or the form of the dispute changes or because of the revision or the repetition of the trail the court verdict becomes countermanded the late verdict would be ineligible and by the request of the beneficiary the verdict is returned.

And also the first verdict would be contradicted in case of the violation of the law whether the mentioned verdicts are issued from one court or several courts. But at international level since the issued verdicts are on the basis of the various states' rules and regulations and the execution of any one of the two contradictory verdicts means the priority of one of the contradictory verdicts therefore, the best solution seems to be to refrain from the execution of both contradictory verdicts.

\subsubsection{Verdict Cancelation Request}

One of the cases of the obstacles of the arbitration execution is the request of cancelation. This principle that the arbitration verdict is final and the finalization of the case needs to be on the basis of the apposite administration of arbitration agreement, legal principle of and rational performance of the arbitrators and following the precise regulations of arbitration otherwise the arbitration verdict can be countermanded.

In part 4 of the article 34 of the UNCITRAL law it is stated that < court can suspend the trial of the case where the court is requested to countermand the arbitration verdict in case of the demand made by one of the sides to create a chance for the verification of the case via arbitration or other similar measures which can nullify the reasons to cancel the verification of the case would be temporarily suspended $>$ In this case there should be differentiation between the concept of countermanding and the possibility of invalidity which are sometimes called as relative and absolute invalidity.

In relative cancelation (possibility of cancelation) the only one for whom the invalidity provides support has the right to call for invalidity while in absolute invalidity any beneficiary can ask for the invalidity of the verdict from the court and can refrain from following the verdict.

Absolute invalidity principally does not require the court verdict only because there is one arbitration verdict superficially and basically to prove the opposite the invalidity is presented and the court has to announce the invalidity and conclude the difference. In article 33 of the Iran's international trade arbitration law the cases of the arbitration verdict invalidity request has been mentioned. And the cases of the verdict invalidity and impossibility of the administration of the verdict has been mentioned in article 34 of the arbitration law. The cases mostly emphasized to invalidate and nullify through the international legal procedure analysis are such as the lack of the eligibility of the sides, lack of the observance of the trail verification procedures, issuing a verdict beyond the authority of the arbiter, the elements of the opposite verdict with peremptory rules and the state public order of the issuing place or the administration of the verdict. 1985 New York foreign arbitration verdict execution and identification convention in part $\mathrm{f}$ of the section 1 of the article 5 has explained the overstepping of power as follows:

1- The identification and execution of the verdict can be rejected by the person against whom the verdict has been issued that the aforesaid person provides positive documents concerning the:

a) The sides of the arbitration agreement .........because of the lack of eligibility

b) Determining the arbiter or the process of verification for the side against whom the verdict has been issued and inappositely delivered

c) The arbitration verdict is about an issue which was not intended to be referred to the arbitration or it is not 
within the arbitration issue..,

d) The type of the establishing of arbitration authority or the arbitration ceremony in accordance with the mutual agreements of the sides or...

e) The arbitration verdict has not become binding for the sides of the contract or that it is invalidated by the state authority the verdict within the territory or because of the rules and regulations has become invalidated or suspended

On the basis of article 52 of the Washington 1965 convention of dispute settlement caused by investment the verdict invalidation request can be done on the basis of one of the following factors:

a) The arbitration tribunal is not appositely established

b) The tribunal has openly overstepped its jurisprudence

c) One of the members of the tribunal has received bribery

d) One of the basic rules of the trail procedures has been violated

e) When the reasons have not been considered as the base of the judgment

The invalidation request needs to be practiced in 120 days after issuing the verdict or in case of the bribery 120 days after the discovery of the bribery and in any case within three years.

It is evident that the invalidation request is not delivered to the court that has issued it, but by a special triple committee whose members are appointed by the central council of investment dispute settlement and from the cental group of arbiters to be verified.

\section{Conclusion}

The fact that no government is able to benefit from the abandonment of an action or the opposite action is an accepted international law principle and originates from the good will principle. Governments by signing the peaceful settlement of the disputes, differences or accepting the reference of the differences to the arbitration or the international verification through multi lateral negotiation create some assignments for them that in case of disregard or deficiency lead to their international responsibilities. The general rules of responsibility in terms of the violation of the state international commitments is about the cases where between the sides special rules, the international law has predicted new responsibilities for the elimination of the harmful impacts of the wrongdoing state in terms of the responsibilities. Given the priority and superiority of the international responsibilities and commitments of the states over the internal rules and responsibilities and the resulting commitments from them referring to the internal rules and excuses can not be accepted from the states as the obstacles against the execution of international verdicts. A government that by disregarding the international rules and regulations refuses to follow the international verdicts and judicial judgments is required to quit violation and accept the compensation for the damages and not repeating it and finally responsible to make compensation for the harmful actions taken in advance. Making compensation caused by the lack of the arbitration verdict execution in the form of compensation as replacement (by considering two elements of possibility and proportion) financial compensation, satisfying the damaged party, announcing the wrong action by the arbitration tribunal or the international judicial court and the damaging country is possible. But in spite of that the damage compensation on people is usually done through the assessment of the inflicted damages and the value of the capital and lack of benefit from the deficiency is carried out. The measure taken for the compensation is usually done by mutual compromise or on the basis of mutual complacency is done. The present on the basis of the international law is generally divided into commitments to result and commitments to behavior (action) and on the basis of the type of the commitment (that commitment is on the basis of action or result) the invalidation of commitment is presented. In fact the invalidation of the commitment is expressed when the behavior of a state is not in proportion with the nature of the commitment that the country has committed. It needs to be clarified that in some cases the commitments of the state by considering the special condition and state of it might be a mixture of commitment to result or commitment to behavior (action). For example the article 3 of the 1985 New York convention is administered in making each side of the committed parties in identifying the binding arbitration verdicts and simultaneous administration of them in accord with state tribunal procedure where the verdict has been executed given the fact that the subject of this article is to identify and execute the arbitration verdicts and it is the responsibility of the state to facilitate the required tools and facilities to administer arbitration verdicts to obtain the results can be placed in the group of commitments to result. The verdicts of international trade chamber arbitration are conclusive and binding (article 28 (6) rules). But the binding quality is different from execution and in case the losing party does not observe the content of the verdict voluntarily there is no choice 
but to obligate him via the internal tribunals of the state of accommodation or the place of the property by referring to the court and asking for the identification and execution of the verdict. The execution of the arbitration verdict at this stage is dependent and decided on the basis of the internal rules of the execution country and to what extend consider it eligible and indentify it and then issue the (administrative) execution order. However, on the basis of arbitration rules article 35 the arbitration authority and the chamber arbitration court makes attempts to execute the verdict and the purpose is mostly the official measures rather than judicial or administrative. Principally, the execution of arbitration verdicts depend on state rules and regulations where from the identification and administration of verdict is requested. In case it is confronted with principal problems such as (the overstepping of the arbiter from the jurisdiction or the violation of public order etc.) can not be identified and executed. At the present time in case a verdict by the international trade chamber arbitration is referred to the Iranian courts would be dealt with on the basis of the foreign rules execution of the general rules and regulations (such as the article 169 of the civil law procedure passed in 1977 and also the articles 972 afterwards of the civil law procedure). But the article 33 and 34 of the arbitration law has predicted that is special to international laws that are executed in Iran. But it can be practiced as the Iranian rules and regulation in terms of the international arbitration rules and it is in line with the judicial procedure to eliminate the ambiguities of this field.

\section{References}

Abbasi Hayati, A. (2006). the explanation of the civil law procedure legal deputy of the judiciary system. Salsabil publication.

Abdollah, S. (2005). civil law procedure V.3 Derak publication.

Afshar, S., \& Mohsen, S. (2003). civil law procedure and trade. Tehran, Jahad Daneshgahi.

Ahmadi, N. (1991). civil law procedure. Tehran, Atlas.

Amir Moezi, A. (2012). Trade international arbitration. Dadgostar.

Bageri, S., \& Javad, M. (2001, Autumn). The impact of the enjoinment of Iran to the New York convention 1958 in terms of the identification and execution of the foreign rules. judicial journl of law, (36).

Bagner, H. (2001). confidentiality -a fundamental principle in intrenational commereial arbitratiin? Journal of international, 18(2).

Civil law procedure passed in 2000.

Hashemi, S. R. (2011). internal rules guaranty of execution 2011.

International trade arbitration chamber procedure.

Iranian international trade arbitration law passed in 1997.

Joneydi, L. (2008). foreign trade arbitration verdicts (2nd ed.). Shahre danesh.

Kaj, K. (n.d.). arbiters mayhem standards, translated by Ebrahim gol, legal journal, Islamic Republic of Iran international legal services N.36.

Kalantariyan, M. (1994). Davari international legal service. Bayyene publication.

Karimi, A. (2008). civil law procedure lesson pamphelets 3, Payame nur.

Katoziyan, N. (1990). the general rules of the contracts V.2 Behnashr publication.

Laliyo, P. (1994). international rules execution, translated by Susan Khatatan. international law.

Madani, J. (1993). civil law procedure. Tehran Ganje danesh, V.

Mohed, M. (1995). civil law procedure lessons of oil arbitration V.1 Islamic Republic of Iran international legal services.

New York foreign arbitration execution and identification convention 1958.

Shiravi, A. (2013). international tarde arbitration (2nd ed.). humanitarian affairs organization publications.

Zeraat, A. (2007). civil law procedure introduction. Tehran gognus.

\section{Notes}

Note 1. Shiravi, Abdolhosein, international trade arbitration second edition, Tehran, publication organization and the humanitarian activities foundation 2013,p.8. 
Note 2. Part a) of the article 1 international trade arbitration law passed in 1997.

Note 3. WIPO Arbitration Rules (1994).

Note 4. Kalantarian, Morteza, Arbitration, International law service office Bayyene publications 1994, p.17.

Note 5. articles 454, 455, civil law procedure.

Note 6. Shams Abdollah civil judiciary rules, Darak publications, Third edition, 2005, V.3, P.308.

Note 7. In this case the practical procedure is that the sides of the action attend the court and announce their agreement to the court or that do their agreement in the official bureau the court after making an agreement a cautionary time is determined and issue the case reference to the court for arbitration.

Note 8. Amir moezzi, international arbitration at commerce cases, Dadgostar, 2012, p. 270.

Note 9. Independent arbitration contract from the main contract which is technically referred to as submission agreement or agreement to arbitrate.

Note 10. ibid, p.270.

Note 11. Amir Moezzi,ibid, p.272.

Note 12. Arbitration clause.

Note 13. Amir Moezzi,ibid, p.125.

Note 14. Article 455 of the civil law.

Note 15. Article civil law.

Note 16. Article 481 civil law despite the verdict of article 185 of the civil law it should be stated that, the essential agreement in addition to the fact that can not be cancelled by one of the sides and can not be cancelled by his death.

Note 17. Article 105 of the civil law.

Note 18. Ahmadi Nemati, civil law procedure, Tehran, Atlas, 1991, pp. 474 and 475.

Note 19. Some of the professors of law have certainly accepted arbitration necessity without any doubt cf. Shams Abdollah, V.3 P.514.

Note 20. Abbas Hayati Ali, civil law procedure description of the judicial deputy Salsabil publications, 2006, P. 647 , to 651 .

Note 21 . Articles 62 of the civil law procedure states that the verification in the court includes all possibilities of referring to the verification except for what the client has called as exception but the authority of the lawyer should be explicitly referred in the agreement...6- The attorney in referring the cases to the arbitration and the determination of arbiter".

Note 22. Article 475 of the civil law procedure.

Note 23. Karimi, Abbas, civil law procedure lesson notebooks 3 Payame nur 2008, p.110.

Note 24. KJ Christopher referees' mayhem standards and principles Alireza Ebrahim gol, legal magazine, central publication of Islamic Republic of Iran international legal service centerN.36, P.59.

Note 25. Article one of the New York convention of identification and administration of foreign arbitration -1958 .

Note 26. Shariat Bageri Mohammad javad, The impacts of the involvement of Islamic Republic of Iran to the New York convention 1958, about the identification and execution of the foreign rules and regulations, legal judicial journal Autumn 2001, N.36 p.52.

Note 27. Hashemi, Seyyed Reza, internal verdicts execution judgment journal, 2011, N.71, P.47.

Note 28. Hashemi, ibid, p.48.

Note 29. Hashemi, ibid, p.49

Note 30. Laliyo, Pier, international arbitration verdict execution Susan Khattatan, international legal services, N. $16^{\text {th }}$ and $17^{\text {th }} 1993, \mathrm{p} .161$.

Note 31. Joneidi, Laya, foreign trade arbitration verdicts execution, second edition, Tehran, Shahre Danesh, 2008, p.31. 
Note 32. ibid,p.35.

Note 33. Hans Bagner ,"confidentiality -a fundamental principle in intrenational commereial arbitratiin?" Journal of international, vol .18.No .2. 2001,43.

\section{Copyrights}

Copyright for this article is retained by the author(s), with first publication rights granted to the journal.

This is an open-access article distributed under the terms and conditions of the Creative Commons Attribution license (http://creativecommons.org/licenses/by/3.0/). 